\title{
Salinomycin Toxicosis in Broiler Breeders and Turkeys: Report of the First Case
}

\author{
${ }^{1}$ Konstantinos C. Koutoulis, ${ }^{2}$ George Kefalas and ${ }^{3}$ Evangelos Minos \\ ${ }^{1}$ Department of Avian Medicine, Faculty of Veterinary Science, \\ School of Health Sciences, University of Thessaly, 43100 Karditsa, Greece \\ ${ }^{2}$ Nuevo SA, 34600 New Artaki, Greece \\ ${ }^{3}$ Poultry Cooperative of Arta, 47100 Arta, Greece
}

Received 2013-08-05, Revised 2013-09-13; Accepted 2013-09-26

\begin{abstract}
The objective of this study was to describe two clinical cases of toxicosis by accidental administration of salinomycin in feed in broiler breeders and turkeys. In the first clinical case, a 32000 broiler breeders flock, 30 weeks of age, suffered a severe mortality during the first week, a sharp decrease in egg production and a dramatic reduction in food consumption together with an increase of eating time. The pathological condition manifested itself mainly with leg paralysis and reluctance to move. In necropsy, signs of bile hyper-secretion, absence of feed in the digestive tract, liver degeneration, egg peritonitis, enlarged kidneys and spleen atrophy were found. Serological examinations for IBV, IBD, NDV, Mg, Ms, Ort, TRT, AE and CAA were negative. The broiler breeders flock was finally euthanized due to an irreversible condition, slow recovery and poor production indicators. In the second clinical case, a flock of 27000 turkeys fatteners, aged from 20 to 35 days, showed an increased daily mortality up to 10 and a $88 \%$ total death loss in 2 weeks period. The turkeys showed great growth retardation, reluctance to move and eat, ataxia and absence of gross lesions, except atrophy of the spleen and pica. Serological examinations for NDV and AI were negative. After removal and change of feed, the remaining flock recovered normally. These two clinical cases were initially associated with incorrect diet and, after obtaining detailed clinical history, laboratory tests and food analysis, the by error administration of salinomycin in feed was confirmed. The final concentrations of salinomycin in feed analysis reached 64.6-124 mg kg${ }^{-1}$ for the broiler breeders and 298-944 $\mathrm{mg} \mathrm{kg}^{-1}$ for turkeys. While salinomycin toxicosis has been reported worldwide in the literature in a number of animal species, including turkey breeders and fatteners with similar symptoms, in broiler breeders has never been reported on the field.
\end{abstract}

Keywords: Broiler Breeders, Feed, Salinomycin, Toxicosis, Turkeys

\section{INTRODUCTION}

Coccidiosis is still considered worldwide as one the most important diseases, affecting performance of the birds and causing major economic losses in the poultry industry. Several protozoan parasites species of the genus Eimeria, developing within the intestine of most domestic and wild animals and birds are the main cause of the disease in broilers and turkeys (De Gussem, 2007). For the control of coccidiosis in poultry, a number of 2000). Salinomycin has been used worldwide for many University of Thessaly, 43100 Karditsa, Greece Tel: +30-24410-66015 Fax: +30-24410-66041 
years in a variety of species such as broilers, replacement chickens and rabbits. Clinical cases of salinomycin toxicosis in turkeys have been described worldwide (Andreasen and Schleifer, 1995), but also in Greece (Githkopoulos and Lekkas, 1990).

The present report describes two unusual cases of salinomycin toxicosis. In the first case, turkeys fatteners were fed accidentally feed concentrate for broilers and in the second one, for the first time in literature, a flock of broiler breeders was fed by error broiler premix in the feed and was euthanized.

\section{CASE REPORT}

\subsection{Broiler Breeders Case}

\subsubsection{Flock Details}

The reported case occurred in a broiler breeders farm located in Arta, in the Southern part of Ipirus region, Greece. A flock of 32,000 Cobb broiler breeders, 30 weeks of age, was housed in four (4) different houses under intensive and controlled environment system. The farm was completely isolated, with high standards of biosecurity and held complete records of feed and water consumption, daily production data and veterinary instructions.

\subsection{Clinical History}

The flock was vaccinated against coccidiosis (Paracox-8, MSD Animal Health) at day 5 in the water and no production problems were observed up to 30 weeks of age. The production data were accordingly to the breed standards, with $82 \%$ egg production and increasing, a feed consumption of 165 grams per day within $3 \mathrm{~h}$ in a mash form and weekly mortality of $0.2 \%$. No signs of any disease manifestation were shown. At the onset of $31 \mathrm{st}$ week of age, the production data changed dramatically. The total weekly mortality raised up to $10 \%$, the egg production dropped sharply to $40 \%$ and the birds literally stopped eating, reducing the feed consumption by $85 \%$, increasing the eating time by $7 \mathrm{~h}$ and consuming only $25 \mathrm{grs}$ in $10 \mathrm{~h}$ period.

\subsection{Clinical Examination}

During the clinical inspection of the flock, the main symptoms observed were leg paralysis, reluctance to move, creamy diarrhea, inappetance, prosternation and high mortality. In necropsy, signs of bile hypersecretion, total absence of feed in the digestive tract, hydropericardium, liver degeneration, egg peritonitis, enlarged kidneys and spleen atrophy (Fig. 1A-C) were found. No other pathognomonic postmortem lesions were recorded.
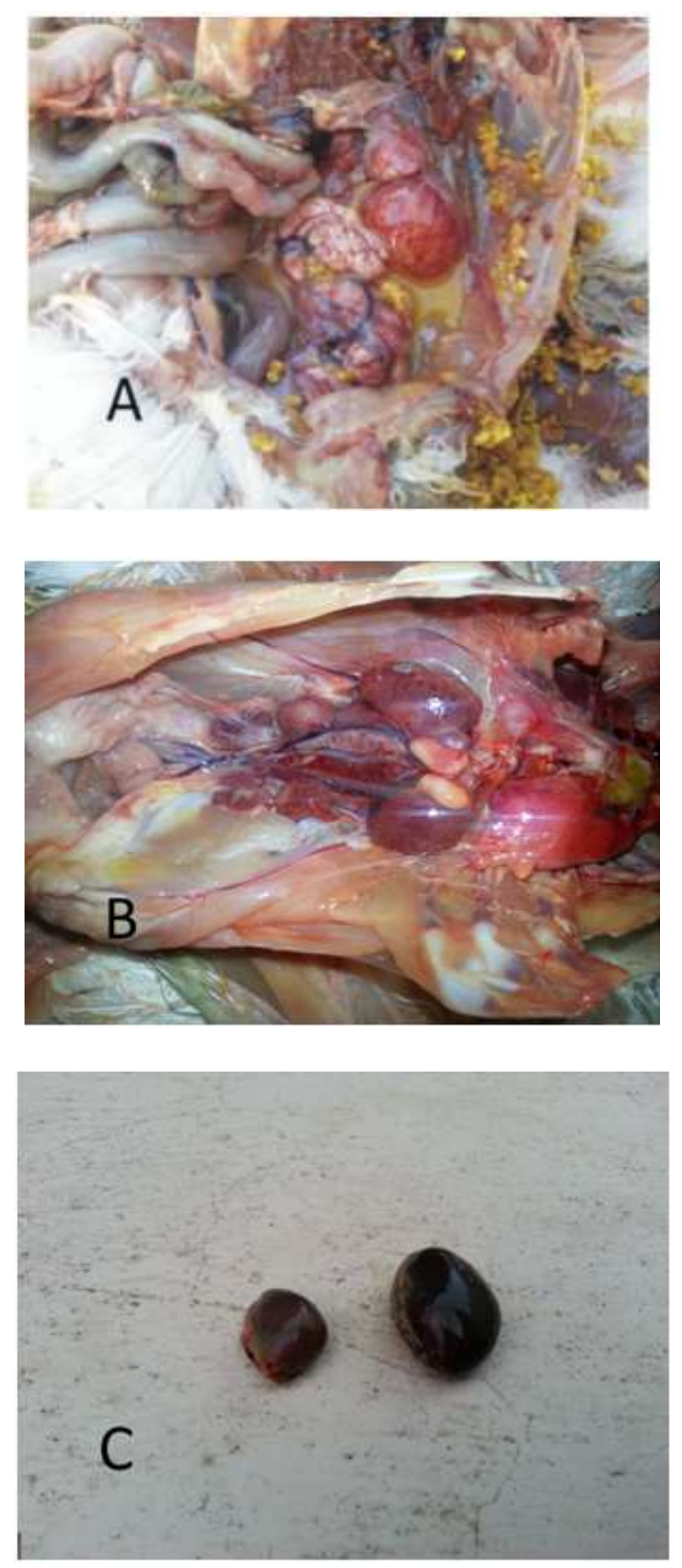

Fig. 1. (A) Liver degeneration and egg peritonitis, (B) Enlarged kidneys in male broiler breeder, (C) Spleen atrophy on the left compared with a normal sized spleen 


\section{4. Sample Collection and Laboratory Examination}

Serological examinations, conducted by ELISA (BioCheck, Holland), for IBV, IBD, NDV, Mg, Ms, Ort, ART, AE and CAA were negative. A new batch of a feed supplement was introduced to the broiler breeders diet in the farm within the preceding 2 days. Therefore, laboratory analysis of the final broiler breeder feed, taken from the feeders on the day of the initial appearance of the condition and another one two days later and breeder feed premix for heavy metals (Salamon and Seaber, UK), monensin and salinomycin (FASFC, Belgium) was also conducted and the results are presented in Table 1.

\subsection{Treatment}

In order to support the health of the birds, therapeutic application of hylectrolytes, multivitamins, vitamin $\mathrm{E}$ and selenium, as well as medication, on the following days were given, but no satisfactory results were produced.

\subsection{Outcome}

No major improvement in production data was noted during the 5 weeks period since the manifestation of the condition. Therefore, the broiler breeders flock was euthanized due to an irreversible condition, slow recovery and poor production indicators.

\subsection{Turkeys Case \\ 2.7.1. Flock Details}

The second reported case occurred in a flock of 27000 heavy breed turkeys fatteners located in Larissa, in the area of Central Thessaly, Greece. The flock was housed in three (3) different open houses and the placement of the one day-old turkey poults was done in three stages: (1) 8000 day-old turkey poults purchased from a local hatchery, (2) 12000 day-old turkey poults originated from farmer's breeders flock, hatched in the same hatchery, 10 days later and (3) 7000 day-old turkey poults purchased from the same local hatchery 5 days later from the latter placement.

\subsection{Clinical History}

The flock was not vaccinated against coccidiosis or any other disease. The feed was produced in farmer's feed mill based on wheat, maize, soya bean and feed concentrate ( $10 \%$ inclusion ratio). No health or production problems were reported and the production data were within the breed standards with a total mortality of $2 \%$. At the onset of 6 th week of age, the daily mortality, initially in the older flock at the age of 35 days, increased dramatically and the consumption of feed reduced by almost $95 \%$. Gradually and within 3 days, the signs of the condition were manifested in the rest of the flocks. In two weeks period, the daily mortality fluctuated from 1 to $10 \%$ and the total mortality reached $88 \%$. Diagnosis for air sacculitis and subsequent treatment given by a local veterinarian were unsuccessful.

\subsection{Clinical Examination}

Live and newly dead turkeys were submitted to the Department of Avian Medicine in Faculty of Veterinary Science, University of Thessaly, for clinical examination, necropsy and laboratory analysis two weeks after the manifestation of the condition. According to the farmer and the local veterinarian, the main symptom was the high mortality and sudden deaths. During the clinical examination of the submitted turkeys, extended growth retardation (Fig. $\mathbf{2 A}$ ), reluctance to move and eat and signs of ataxia were recorded. In necropsy, total absence of feed in the digestive tract together with pica (Fig. 2B) and spleen atrophy (Fig. 3A-B) were found. Absence of other pathognomonic postmortem lesions was recorded.

\subsection{Sample Collection and Laboratory Examination}

Due to the acute manifestation and progress of the condition, serological examinations, conducted by ELISA (BioCheck, Holland), for notifiable diseases NDV and AI were done with negative results. A new batch of a feed supplement was introduced to the turkey's diet in the farm within the preceding 2 days, using a new batch of concentrate. Therefore, laboratory analysis in two different samples of turkey's feed concentrate for salinomycin, taken on the day after the clinical examination in the Department of Avian Medicine, was also conducted (Agrolab SA and Biolab Epirus, Greece) and the results are presented in Table 1.

\subsection{Treatment}

Hylectrolytes, multivitamins, vitamin $\mathrm{E}$ and selenium were supplemented in the water in an attempt to boost the health of the birds. Complete removal of the old feed, change of feed concentrate and use of new ingredients were immediately applied. 
Konstantinos C. Koutoulis et al. / American Journal of Animal and Veterinary Sciences 8 (4): 190-196, 2013

Table 1. Laboratory analysis of final feed, premix and concentrate in the reported clinical cases

\begin{tabular}{|c|c|c|c|c|c|}
\hline & \multicolumn{2}{|c|}{ Broiler breeders } & \multirow[b]{2}{*}{ Feed Premix } & \multicolumn{2}{|l|}{ Turkeys } \\
\hline & Sample 1 & Sample 2 & & Concentrate 1 & Concentrate 2 \\
\hline Lead $(\mathrm{Pb}) \mathrm{mg} / \mathrm{kg}$ & 4.2 & - & - & - & - \\
\hline Arsenic (As) mg/kg & 0.2 & - & - & - & - \\
\hline Cadmium (Cd) $\mathrm{mg} / \mathrm{kg}$ & 0.2 & - & - & - & - \\
\hline Mercury $(\mathrm{Hg}) \mathrm{mg} / \mathrm{kg}$ & $<0.5$ & - & - & - & - \\
\hline Selenium (Se) $\mathrm{mg} / \mathrm{kg}$ & 6 & - & - & - & - \\
\hline Monensin mg/kg* & $<0.2$ & $<0.2$ & $<0.2$ & - & - \\
\hline Salinomycin $\mathrm{mg} / \mathrm{kg}$ * & 124 & 64.6 & $<0.2$ & 298 & 944 \\
\hline
\end{tabular}

Sample 1 and 2: Broiler breeder feed sample taken from the feeders on the day of condition's manifestation and two days later respectively. Feed Premix: Broiler breeder premix was manufactured by external supplier.

Concentrate 1 and 2: Turkeys concentrate taken from two different batches on necropsy's following day and it was manufactured by external supplier.

*All samples for coccidiostat analysis were analyzed by LC-MS/MS
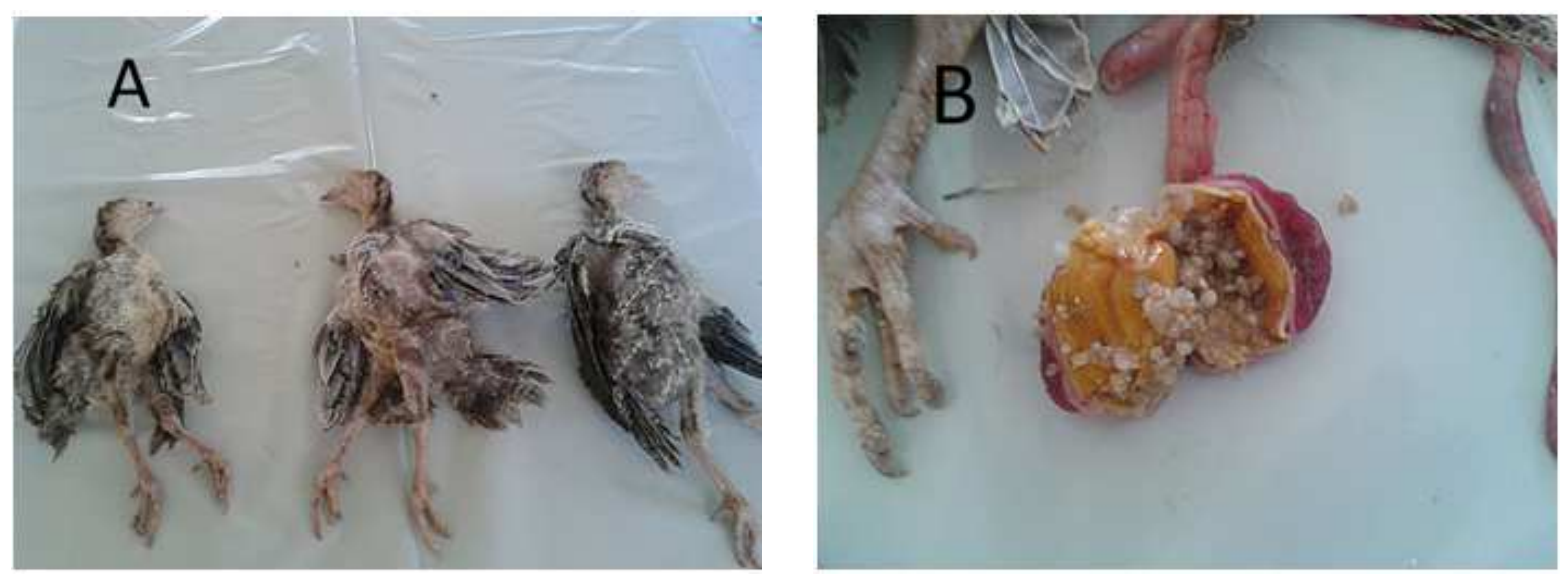

Fig. 2. (A) Growth retardation in 35 days old poults, (B) Pica: Gravels in turkey's stomach
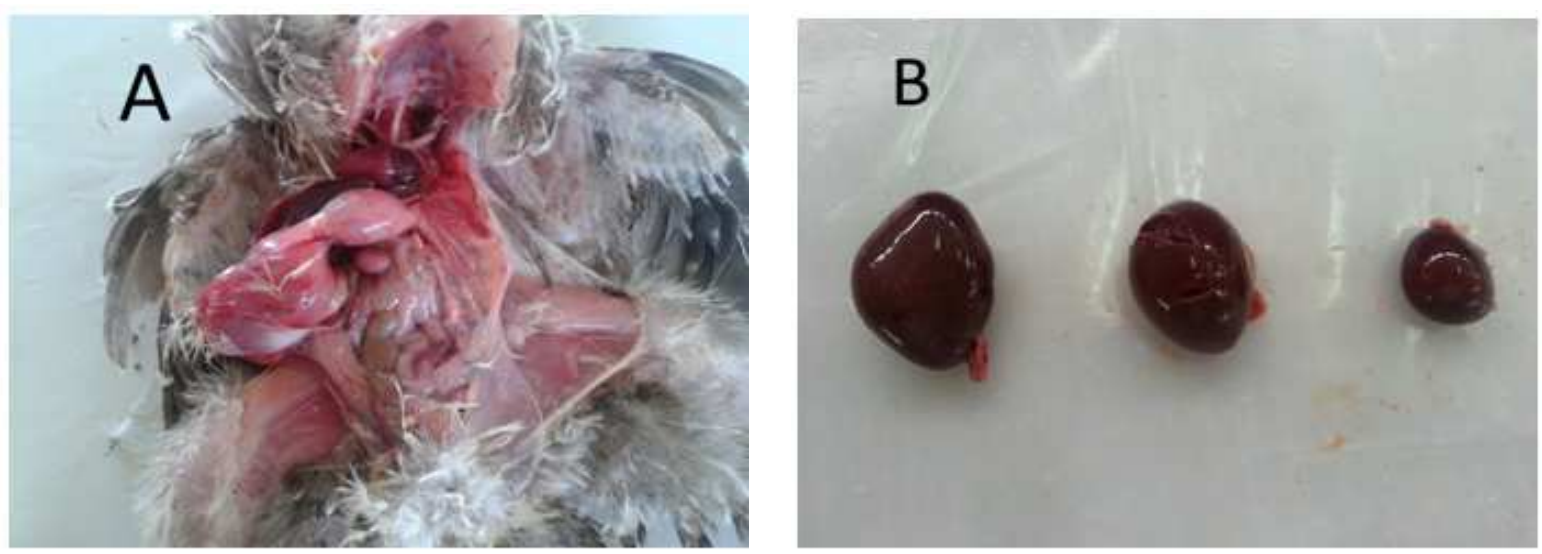

Fig. 3. (A) Spleen atrophy. No other pathognomonic gross lesions were recorded, (B) Spleen atrophy on the right compared with normal sized spleens on the left and on the middle 


\subsection{Outcome}

After removal and change of feed, the remaining flock (3240 turkeys) recovered normally with a major improvement in health and production data and with no evidence of lesions that would render the product unfit for human consumption.

\section{DISCUSSION}

In the current study, two clinical cases of salinomycin toxicosis in broiler breeders and turkeys were described. Salinomycin was used in high concentration in feed by mistake in both cases and caused major problems on the health and productivity of the flocks. Like humans, animals may experience adverse effects when treated with medicinal products. These effects may be related to the pharmacological or toxicological properties of the substances used or they may arise because of hypersensitivity (Woodward, 2005).

Ionphore toxicity, often with fatalities and frequently as a result of accidental treatment or misuse, has been reported in a number of species including dogs, cats, quail, chickens, ostriches, goats, pigs, sheep, cattle, camels and horses (Malone, 1978; Howell et al., 1980; Chalmers, 1988; Sawant et al., 1990; Gregory et al., 1992; Mousa and Elsheikj, 1992; Andreasen and Schleifer, 1995; Plumlee et al., 1995; Hoop, 1998; Linde-Sipman et al., 1999; Bila et al., 2001; Agaoglu et al., 2002). Relatively low doses of ionphores can also be toxic to turkeys (Potter et al., 1986; Ficken et al., 1989) and their toxicity may be potentiated by other substances and notably by the antimicrobial drug tiamulin (Bartov, 1994; Wendt et al., 1997). Salinomycin has been used worldwide for many years in broilers and replacement chickens, but its accidental use in turkeys has caused major problems worldwide (Van Assen, 2006; Halvorson et al., 1982).

Previous report have suggested that salinomycin toxicosis in turkeys fatteners can cause major problems and increased mortality (Van Assen, 2006). This seems to correlate with other studies, which have stated that salinomycin poisoning could severely affect the health status of point-of-lay and breeder turkeys as well (Andreasen and Schleifer, 1995; Griffiths et al., 1989). In this study, similar symptoms, including signs of ataxia, pica and spleen atrophy were also noted, indicating that turkeys are very sensitive to salinomycin regardless of age or type of production. The current results also indicated that older turkeys manifested the condition sooner than the younger ones, even if they consumed the same feed at the same time. This might be associated with the increased appetite of the older birds and thus, correlate well with the amount of toxin ingested. It is well known that salinomyccin become more toxic as the age of the turkeys increase (Potter et al., 1986). In this study, the clinical signs of salinomycin toxicosis in broiler breeders were recorded on field for a first time in literature. During the clinical inspection of the flock, similar symptoms as leg paralysis, high mortality and spleen atrophy were recorded, but also, liver degeneration, egg peritonitis, enlarged kidneys and hydropericardium were found. Cardiomyopathy and myopathies have been seen in various species with ionophore poisoning (Hanrahan et al., 1981; Muylle et al., 1981; Anderson et al., 1984), but never before in broiler breeders. Also in this study, a significant drop in egg production was noted, whereas Jones et al. (1990) noted that salinomycin at a level of $60 \mathrm{mg} \mathrm{kg}^{-1}$ in feed caused a significant drop in hatchability, but not in egg production.

According to European Commision Regulation (ECR, 2007), salinomycin is used legally for the prevention of coccidiosis in broiler chickens at a level of $60-70 \mathrm{mg} \mathrm{kg}^{-1}$ and is not allowed in horses and turkeys. In this study, these two clinical cases were linked immediately with incorrect diet and, after studying the history, running laboratory tests and food analysis, the by error administration of salinomycin in the premix and in the concentrate provided to broiler breeders and turkeys respectively were confirmed. New feed batches was fed to both flocks mistakenly contained a broiler concentrate, instead of a turkeys concentrate and a broiler premix instead of a premix manufactured for breeders. The final concentrations of salinomycin in the feed reached $64.6-124 \mathrm{mg} \mathrm{kg}^{-1}$ for the broiler breeders and $298 \mathrm{mg} \mathrm{kg}^{-1}$ for turkeys. By $10 \%$ dilution, the turkeys concentrate provided 29.8-94.4 mg kg-1 of salinomycin in the final feed. Apart from the improper use of salinomycin in both flocks, the final dosage was almost doubled the level allowed according to EC Regulation (60-70 $\mathrm{mg} \mathrm{kg}^{-1}$ ). This dosage was even higher than those reported in previous studies (Van Assen, 2006; Andreasen and Schleifer, 1995; Griffiths et al., 1989; Jones et al., 1990).

This study highlights the necessity for an effective educational plan applied to feed mill personnel and to the farmers. Measures should be taken to ensure food safety for the flock and consumer food safety included feed 
record studies, on-farm veterinary consultation, diagnostic laboratory studies and food animal residue consultation (Van Assen, 2006). Producers who realize the meaning of food safety could produce products with high quality. There is also a need for transparency of information between veterinarian and producer. The development of an Hazard Analysis Critical Control Points (HACCP) for feed mills and farms could minimize mistakes and ensure that a safe product is produced more consistently. The feed mill personnel should be educated constantly on issues concerning the importance of ionphores-antibiotics compatibility and scheduled controls of composition-homogeneity of feed. Veterinarians can provide more complete information on the safe use of products and the risks of improper use. The expert-mediated advice on any inquiry related to drug or chemical residues in food animals retains its value because recommendations are made based on the best scientific evidence available, should problems arise.

\section{CONCLUSION}

In conclusion, salinomycin toxicosis causes severe health and production problems in turkeys and broiler breeders. Therefore, veterinarians should help to educate clients about potential problems with contaminated or toxic feeds, in both feed mill and farming level.

\section{REFERENCES}

Agaoglu, Z.T., Y. Akgul, I. Keles, S. Ugras and A. Aksoy et al., 2002. Accidental salinomycin toxicity intoxication of Angora goats in Turkey. Small Ruminant Res., 45: 159-161.

Anderson, T.D., W.G.V. Alstine, M.D. Ficken, D.W. Miskimins and R.L. Carson et al., 1984. Acute monensin toxicosis in sheep: Light and electron microscopic changes. Am. J. Vet. Res., 45: 11421147. PMID: 6742573

Andreasen, J.R. and J.H. Schleifer, 1995. Salinomycin toxicosis in male breeder turkeys. Avian Dis., 39: 638-642. PMID: 8561753

Bartov, I., 1994. Effect of growth promoters on monensin toxicity in broiler chicks. Br. Poultry Sci., 35: 123-133. DOI: 10.1080/00071669408417677

Bila, C.G., C.L. Perreira and E. Gruys, 2001. Accidental toxicosis in horses in Mozambique. J. South Afr. Vet. Associat., 72: 163-164. PMID: 11811705

Chalmers, G.A., 1988. Alberta. Monensin toxicity in dogs.. Canadian Vet. J., 29: 459-459.
Chapman, H.D., T. Cherry, H. Danforth, G. Richards and M. Shirley et al., 2002. Sustainable coccidiosis control in poultry production: The role of live vaccines. Int. J. Parasitol., 32: 617-629. PMID: 11943233

De Gussem, M., 2007. Coccidiosis in poultry: Review on diagnosis, control, prevention and interaction with overall gut health. Proceedings of the 16th European Symposium on Poultry Nutrition, (SPN' 07), Strasbourg, France, pp: 253-261.

ECR, 2007. Amending Regulation (EC) No 1463/2004 as regards the introduction of a maximum residue limit for the feed additive 'Sacox 120 microGranulate', belonging to the group of coccidiostats and other medicinal substances. Official J. EU, L 118: 3-4.

Ficken, M.D., D.P. Wages and E. Gonder, 1989. Monensin toxicity in turkey breeder hens. Avian Dis., 33: 186-190.

Githkopoulos, P. and S. Lekkas, 1990. Salinomycin poisoning in turkeys. Bull. Hellenic Vet. Med. Soc., 41: 3-10.

Gregory, D.G., W.C. Edwards and E.L. Stair, 1992. A case of monensin poisoning in ostriches. Vet. Hum. Toxicol., 34: 247-247. PMID: 1609499

Griffiths, G.L., R. Hillier and R.J. Sutherland, 1989. Salinomycin poisoning in point-of-lay turkeys. Aus. Vet. J., 66: 326-329.

Halvorson, D.A., C.V. Dijk and P. Brown, 1982. Ionophore toxicity in turkey breeders. Avian Dis., 26: 634-639. PMID: 7150149

Hanrahan, L.A., D.E. Corrier and S.A. Nagi, 1981. Monensin toxicosis in broiler chickens. Vet. Pathol., 18: 665-671. PMID: 7281463

Hoop, R.K., 1998. Salinomycin toxicity in layer breeders. Vet. Record, 142: 550-550. PMID: 9637384

Howell, J., J. Hanson, D. Onderka and W.N. Harries, 1980. Monensin toxicity in chickens. Avian Dis., 24: 1050-1053. PMID: 7271636

Jones. J.E., J. Solis, B.L. Hughes, D.J. Castaldo and J.E. Toler, 1990. Reproduction responses of broiler breeders to anticoccidial agents. Poultry Sci., 69: 2736. DOI: $10.3382 /$ ps.0690027

Linde-Sipman, J.S.V.D., T.V.D. Ingh, J.J.V. Nes, H. Verhagen and J.G.T.M. Kersten et al., 1999. Salinomycin induced polyneuropathy in cats. Morphologic and epidemiologic data. Vet. Pathol., 36: 152-156. PMID: 10098644 
Lindsay, D.S. and B.L. Blagburn, 2001. Antiprotozoan Drugs. In: Veterinary Pharmacology and Therapeutics, Adams, H.R. (Ed.), Wiley, Ames, ISBN-10: 0813817439, pp: 992-1016.

Malone, P., 1978. Monensin sodium toxicity in cattle. Vet. Record, 103: 477-478. PMID: 741611

Mousa, H.M. and H.A. Elsheikh, 1992. Monensin poisoning in dromedary camels. Deutsche Medizinische Wochenschrift, 99: 464-464. PMID: 1459038

Muylle, E., C. Vandenhende, W. Oyaert, H. Thoonen and K. Vlaeminck, 1981. Delayed monensin sodium toxicity in horses. Equine Vet. J., 13: 107-108. DOI: 10.1111/j.2042-3306.1981.tb04129.x

Oehme, F.W. and W.K. Rumbeiha, 2000. Veterinary Toxicology. In: General and Applied Toxicology, Ballantyne, B., T. Marrs and T. Syversen (Eds.), Stockton Press, Basingstoke, ISBN-10: 561592420, pp: 1509-1526.

Plumlee, K.H., B. Johnson and F.D. Galey, 1995. Acute salinomycin toxicosis of pigs. J. Vet. Diagnostic Investig., 7: 419-420. PMID: 7578468
Potter, L.M., J.P. Blake, M.E. Blair, B.A. Bliss and D.M. Denbow, 1986. Salinomycin toxicity in turkeys. Poultry Sci., 65: 1955-1959.

Sawant, S.G., P.S. Terse and R.R. Dalvi, 1990. Toxicity of dietary monensin in quail. Avian Dis., 34: 571574. DOI: $10.2307 / 1591246$

Van Assen, E.J., 2006. A case of salinomycin intoxication in turkeys. Canadian Vet. J., 47: 256-258.

Wendt, M., S. Busing and W. Bollwahn, 1997. Toxicity of the combination of salinomycin and tiamulin in swine. Deutsche Tierarztliche Wochenschrift, 104: 405-410. PMID: 9410734

Woodward, K.N., 2005. Veterinary pharmacovigilance. Part 3. Adverse effects of veterinary medicinal products in animals and on the environment. J. Vet. Pharmacol. Therapeut., 28: 171-184. DOI: 10.1111/j.1365-2885.2005.00647.x 